\title{
Karyotype studies on populations of two Hypochaeris species (H. catharinensis and H. lutea), Asteraceae, endemics to southern Brazil
}

\author{
F.G. Fiorin'1, P.M. Ruas ${ }^{1}$, M.A. Ortiz ${ }^{2}$, E. Urtubey ${ }^{3}$, N.I. Matzenbacher ${ }^{4}$ \\ and C.F. Ruas ${ }^{1}$ \\ ${ }^{1}$ Departamento de Biologia Geral, Centro de Ciências Biológicas, \\ Universidade Estadual de Londrina, Londrina, PR, Brasil \\ ${ }^{2}$ Departamento de Biología Vegetal y Ecología, Universidad de Sevilla, \\ Sevilla, Spain \\ ${ }^{3}$ Instituto de Botánica Darwinion, San Isidro, Argentina \\ ${ }^{4}$ Departamento de Botânica, Universidade Federal do Rio Grande do Sul, \\ Porto Alegre, RS, Brazil \\ Corresponding author: C.F. Ruas \\ E-mail: ruas@uel.br
}

Genet. Mol. Res. 12 (2): 1849-1858 (2013)

Received February 26, 2012

Accepted August 10, 2012

Published January 4, 2013

DOI http://dx.doi.org/10.4238/2013.January.4.4

\begin{abstract}
Hypochaeris is an excellent system for studying different modes of chromosome evolution in plants. We carried out a cytogenetic analysis on populations of 2 Hypochaeris species, comprising 10 populations of $H$. catharinensis and 5 of $H$. lutea, to assess possible changes on chromosome organization in this interesting genus. Conventional Feulgen staining and fluorescent banding revealed that the general aspects of chromosome morphology for all populations of both species were similar, evidence of the typical bimodal karyotypes with $2 n=8$ chromosomes that characterize the South American Hypochaeris. Comparative analysis of the karyotypes identified minor variations in the absolute size and arm ratio of corresponding
\end{abstract}


chromosome pairs. One population of $H$. lutea was entirely polyploid adding a novel cytotype to this species. Fluorescent banding revealed strong chromomycin $\mathrm{A}_{3}\left(\mathrm{CMA}_{3}\right)$-positive signals on both arms of chromosomes 3 and 4 of $H$. catharinensis, revealing a new pattern for the distribution of GC-rich heterochromatin in Hypochaeris. A strong CMA-positive signal was observed on the short arm of chromosome 3 in one population of $H$. lutea, while the other populations validated the $\mathrm{CMA}_{3}$ pattern already described for this species. While the overall karyotype similarities of the 2 species are in compass with all South American Hypochaeris, the presence of unusual large blocks of GC-rich heterochromatin suggests that chromosome rearrangements, related to dispersion of heterochromatin, are taking place in the karyotype of $H$. catharinensis. The novel polyploid cytotype identified in $H$. lutea provides support that polyploidization is an active process in the mode of chromosome evolution in Hypochaeris.

Key words: Asteraceae; Chromomycin $\mathrm{A}_{3}$ banding; Polyploidy; Karyotype evolution

\section{INTRODUCTION}

The genus Hypochaeris L. (Asteraceae, Lactuceae) presents 2 different centers of distribution with more than 15 species in Eurasia and north of Africa and 40-50 taxa confined in South America (Stebbins, 1971; DeFilips, 1976; Bortiri, 1999). The South American Hypochaeris are apparently, derived from a rapid and recent process of speciation (Tremetsberger et al., 2005), associated with a selection of karyotypes containing a small number of relatively large chromosomes. Differences in basic chromosome numbers $(x=3,4$, 5, and 6) and symmetric karyotypes are typically found in Old World species (Parker, 1976; Mugnier and Siljak-Yakovlev, 1988; Barghi et al., 1989; Siljak-Yakovlev et al., 1994; Hall and Parker, 1995; Cerbah et al., 1998). In contrast, the South American species exhibit a uniform basic chromosome number with $x=4$, associated with a highly asymmetrical and bimodal karyotypes (Stebbins, 1971; Weiss et al., 2003; Ruas et al., 1995, 2005; Weiss-Schneeweiss et al., 2003, 2007, 2008).

Detailed cytogenetic studies, including FISH, are well known for the Old World $H y$ pochaeris. A significant number (25) of species of the South America group were cytogenetically well characterized (Weiss, 2003; Ruas et al., 1995, 2005; Weiss-Schneeweiss et al., 2003, 2007), but approximately half of the species still lacks more comprehensive information. Most of the South American Hypochaeris is diploid with $2 n=8(x=4)$, with occasional occurrence of intraspecific or intrapopulation polyploidy (Weiss et al., 2003; Weiss-Schneeweiss et al., $2003,2007)$. The application of conventional and molecular cytogenetics has permitted the discrimination of 7 karyotype groups among the South American Hypochaeris, providing support for the interspecific relationships within and among this group of species (Cerbah et al., 1998; Weiss et al., 2003; Ruas et al., 2005; Tremetsberger et al., 2006; Weiss-Schneeweiss et al., 2003, 2007, 2008). Recently, using molecular cytogenetics (FISH), Reck et al. (2011) identified a unique $45 \mathrm{~S}$ rDNA signal at the terminal position on the short arm of chromosome 3 of $H$. catharinensis, including this species within the Patagonica karyotype group. 
The aims of the present research comprised karyotype studies in H. catharinensis and H. lutea, endemics to southern Brazil to: a) report for the first time a detailed study on karyotype morphology of $H$. catharinensis by investigating the chromosomes of 10 populations of this species; b) search for chromosome variation in 5 populations of $H$. lutea; c) investigate changes in chromosome structure related to the dispersion of heterochromatin, among karyotypes within and between populations of both species.

\section{MATERIAL AND METHODS}

\section{Plant material}

The present study was composed of chromosome investigation of 2 representatives of the South American group of Hypochaeris species, including 10 populations of $H$. catharinensis Cabrera and 5 populations of $H$. lutea (Vell.) Britton. While both species frequently occur in Rio Grande do Sul and Santa Catarina States, H. catharinensis is the only known representative of the South American Hypochaeris that is endemic to southern Brazil. H. catharinensis is a perennial herb, being the only species of the genus that presents fasciculate roots and a horizontal rhizome, a characteristic of taxonomic importance for this taxon (Azevêdo-Gonçalves and Matzenbacher, 2007). This species typically occurs at high altitude $(800-1400 \mathrm{~m})$ in cold and rocky open areas, in association with herbaceous plants with predominance of grasses and in forests with Araucaria angustifolia. The distribution of $H$. catharinensis includes Santa Catarina State and 2 physiographic areas in the north and northeast of Rio Grande do Sul, with a few occurrences in the borders of the States of Paraná and Santa Catarina (Azevêdo-Gonçalves and Matzenbacher, 2007).

$H$. lutea exhibits wider distribution, occurring predominantly in high, cold, and extremely humid (swampy) areas characterized by thick, black organic soils and a nutrient-rich environment. This species is commonly found in association with hydrophilic species of grasses and Sphagnum, typically in the States of Rio Grande do Sul and Santa Catarina (Matzenbacher, 1998). Some reports on herbarium specimens also describe the occurrence of $H$. lutea also in humid mountain areas of Paraná, São Paulo, Rio de Janeiro, and Minas Gerais States in Brazil, as well as in Uruguay and Argentina (Azevêdo-Gonçalves and Matzenbacher, 2007).

Plants were obtained from 10 natural populations of $H$. catharinensis and of 5 populations of H. lutea. Samples consisted of 20-40 individuals per population. The collected plants were potted and maintained in the greenhouse for further studies. Specimens from each population were deposited in the Herbarium (FUEL) of Departamento de Biologia Animal e Vegetal at Universidade Estadual de Londrina. Table 1 contains information on the plant taxa used in the present study, including accession details and source localities.

\section{Chromosome preparations}

For cytogenetic analysis, root tips were collected and bulked from the potted plants or from germinated seeds, representing each of the 10 populations of $H$. catharinensis and the 5 populations of $H$. lutea. Roots were pretreated with a saturated solution of hydroxyquinolein $\left(0.029 \mathrm{~g}\right.$ in $100 \mathrm{~mL}$ distilled water) for $3: 15 \mathrm{~h}$ at $8^{\circ} \mathrm{C}$, fixed in $3: 1$ absolute ethanol and glacial acetic acid for $12-24 \mathrm{~h}$ at room temperature, and stored at $-20^{\circ} \mathrm{C}$ until use. 
Table 1. Populations of Hypochaeris catharinensis and H. lutea with diploid chromosome number $(2 n)$, collection sites, collectors in parentheses, and voucher numbers (FUEL).

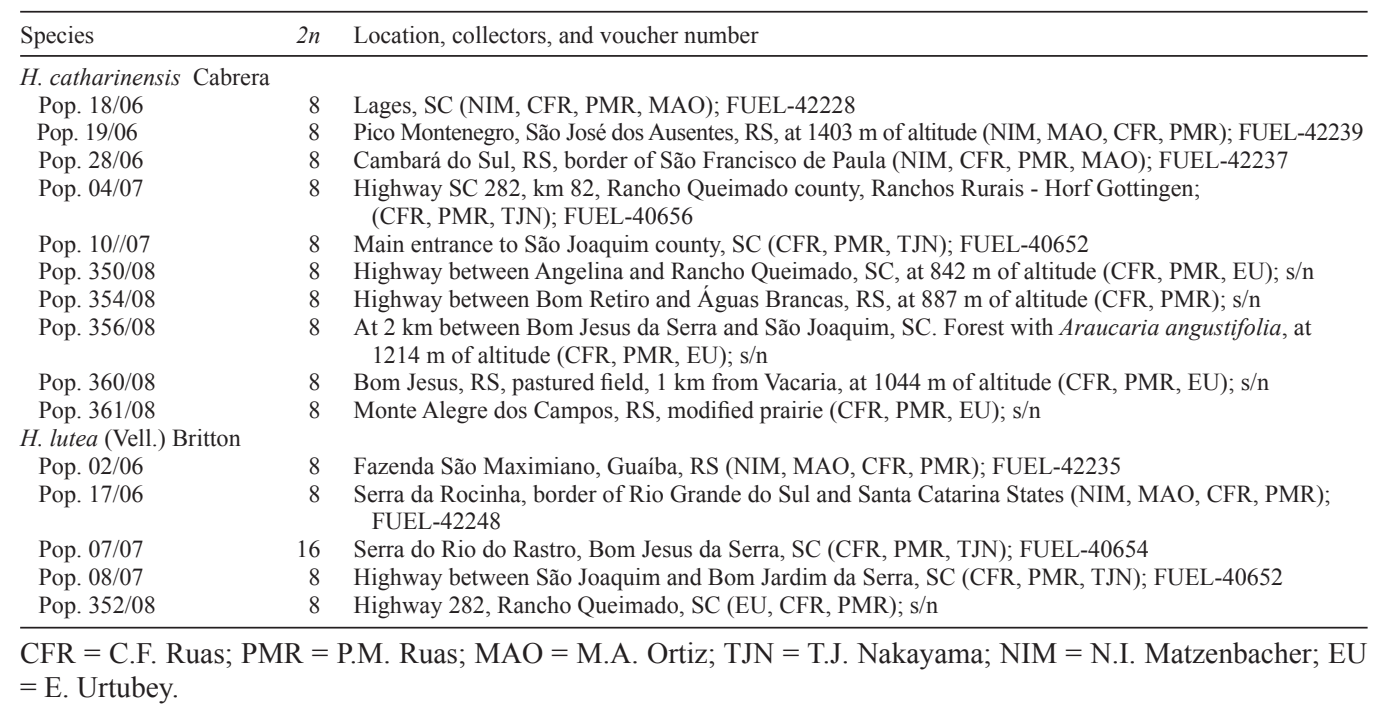

We used the Feulgen method with the Schiff reagent for conventional staining. Meristems were squashed in a drop of $45 \%$ acetic carmine and preparations were sealed with Permount (Sigma, USA). The chromosome counts were determined using at least 20 wellspread metaphase cells for each population of both species. Metaphase cells were examined under a photomicroscope Nikon Eclipse E600, equipped with a photographic camera (Cool SNAP cf, Photometrics, USA) and the images were stored in a computer and processed with Adobe Photoshop, using only those functions that could be evenly applied in the entire image. Chromosome measurements were carried out in at least 5 well-spread metaphases for every population, including the absolute $(\mu \mathrm{m})$ and relative $(\%)$ length of each chromosome pair; the absolute size of the haploid complement $(\mu \mathrm{m})$ and the arm ratio (long arm/short arm) of each chromosome pair. The karyotype asymmetry index was calculated using the following formula: [sum of the long arms of each chromosome pair / haploid length x 100], as described by Arano and Saito (1980), and the ratio of longest/shortest chromosomes. The chromosome types were defined according to Levan et al. (1964), and the numerical parameters of the karyotypes were used to construct the ideograms of $H$. catharinensis and H. lutea.

\section{Chromomycin $\mathrm{A}_{3}\left(\mathrm{CMA}_{3}\right)$ and 4',6-diamino-2-phenylindole (DAPI) banding}

For banding purposes, root tips were hydrolyzed for $5 \mathrm{~min}$ in $45 \%$ acetic acid at $60^{\circ} \mathrm{C}$ and the meristems were squashed in a drop of $45 \%$ acetic acid. After metaphase plate selection with a phase contrast microscope, the coverslips were removed by freezing in liquid nitrogen and the slides were rinsed with absolute ethanol and air dried until use. Two different fluorochrome banding protocols were applied to reveal GC-rich (with $\mathrm{CMA}_{3}$ ) and AT-rich (with DAPI) regions. The procedures are detailed in Ruas et al. (2005). The metaphases were photographed using a Nikon Eclipse E600 photomicroscope equipped with a photographic camera 
(Cool SNAP cf, Photometrics) by using selective filters. The fluorescent images were stored in microcomputer and processed with Adobe Photoshop, using only those functions that could be applied evenly in the entire image.

\section{RESULTS AND DISCUSSION}

\section{Karyotype structure of $\boldsymbol{H}$. catharinensis and $\mathrm{H}$. lutea}

Table 2 contains a summary of the cytogenetic data for all populations of $H$. catharinensis and H. lutea studied. The mitotic metaphases, $\mathrm{CMA}_{3}$ banding, and ideograms of the 2 species are shown in Figures 1 and 2. Detailed chromosome analyses are described for the first time for $H$. catharinensis, adding a new contribution to understanding the mechanisms of karyotype diversification in the South American group of species.

\begin{tabular}{|c|c|c|c|c|c|c|c|}
\hline \multirow[t]{2}{*}{ Species/population } & \multicolumn{7}{|c|}{ Relative chromosome length } \\
\hline & $A s I$ & RI & Chr. 1 & Chr. 2 & Chr. 3* & Chr. 4 & $\mathrm{HCL}(\mu \mathrm{m})$ \\
\hline \multicolumn{8}{|l|}{ H. catharinensis } \\
\hline Pop. 18/06 & 74.19 & 2.98 & 40.47 & 28.99 & 15.20 & 13.58 & $14.80 \pm 0.46$ \\
\hline Pop. 19/06 & 76.43 & 3.01 & 41.97 & 28.73 & 15.35 & 13.95 & $15.70 \pm 0.27$ \\
\hline Pop. 28/06 & 75.49 & 3.08 & 41.07 & 29.62 & 15.16 & 13.51 & $17.22 \pm 0.11$ \\
\hline Pop. 04/07 & 67.60 & 2.53 & 38.58 & 28.51 & 17.30 & 16.60 & $14.26 \pm 0.50$ \\
\hline Pop. $10 / 07$ & 75.05 & 3.01 & 37.39 & 36.35 & 13.84 & 12.42 & $16.27 \pm 0.46$ \\
\hline Pop. $350 / 08$ & 75.58 & 3.34 & 39.96 & 33.45 & 14.48 & 12.28 & $14.29 \pm 0.69$ \\
\hline Pop. $354 / 08$ & 75.31 & 3.01 & 38.22 & 32.75 & 16.34 & 12.69 & $14.26 \pm 0.98$ \\
\hline Pop. $356 / 08$ & 74.63 & 3.53 & 42.98 & 28.09 & 16.70 & 12.26 & $14.31 \pm 0.47$ \\
\hline Pop. $360 / 08$ & 76.33 & 3.59 & 46.03 & 28.43 & 14.28 & 13.32 & $14.49 \pm 0.22$ \\
\hline Pop. $361 / 08$ & 75.58 & 3.59 & 44.58 & 27.49 & 15.51 & 12.39 & $14.44 \pm 0.98$ \\
\hline \multicolumn{8}{|l|}{ H. lutea } \\
\hline Pop. 02/06 & 75.28 & 3.02 & 40.02 & 30.84 & 15.83 & 13.24 & $16.09 \pm 0.61$ \\
\hline Pop. $17 / 06$ & 72.02 & 3.01 & 40.42 & 30.01 & 16.07 & 13.41 & $14.62 \pm 0.35$ \\
\hline Pop. $07 / 07(4 x)$ & 73.30 & 3.62 & 42.38 & 31.40 & 14.49 & 11.69 & $31.12 \pm 1.41$ \\
\hline Pop. $08 / 07$ & 75.90 & 3.16 & 41.42 & 29.66 & 15.80 & 13.11 & $16.32 \pm 0.41$ \\
\hline Pop. $352 / 08$ & 75.46 & 3.66 & 43.90 & 30.97 & 13.13 & 12.00 & $15.08 \pm 0.30$ \\
\hline
\end{tabular}

$A s I=$ asymmetry index; $\mathrm{RI}=$ ratio of longest/shortest chromosome; $\mathrm{HCL}=$ haploid chromosome length. $*$ Secondary constriction on the short arm of chromosome pair 3 .

H. catharinensis shares the basic chromosome number $x=4$, with the asymmetrical and bimodal karyotypes that characterize the South American species of Hypochaeris (Ruas et al., 1995, 2005; Weiss-Schneeweiss et al., 2007, 2008). The typical metaphase and ideogram of $H$. catharinensis are illustrated in Figure 1A and D. Comparative analysis among karyotypes from all populations revealed the absence of significant differences, with only small variations in the absolute size between corresponding chromosome pairs (data not shown), as denoted by the data of the relative length (Table 2). The mean haploid chromosome length among karyotypes also differed slightly, varying from $14.26 \pm 0.50 \mu \mathrm{m}$ for population 04/07 (Rancho Queimado, SC) and 14.26 $\pm 0.98 \mu \mathrm{m}$, for population 354/08 (Bom Retiro, $\mathrm{SC}$ ), to $17.22 \pm 0.11 \mu \mathrm{m}$ for population 28/06 (Cambará do Sul, RS), suggesting that the variation in haploid sizes mostly derived from differences in the chromosome contraction of the metaphases analyzed. The asymmetric index for all populations was high, varying from 67.60 (Pop 04/07, Rancho Queimado, SC) to 76.43 (Pop 19/06, Pico Montenegro, RS), a 
feature that is typical of Hypochaeris from South America. The arm ratio of corresponding chromosome pairs (data not shown) revealed a unique karyotype formula $(2 n=2 \mathrm{~m}+2 \mathrm{~m}$-sat +4 st) for all populations of $H$. catharinensis with pairs 1 and 2 being the same subtelocentric (st) chromosome type, whereas pairs 3 and 4 were identified as metacentric $(\mathrm{m})$ type (data not shown). Although they were not always visible, satellites were identified on the short arms of chromosome pair 3 in $H$. catharinensis, which correspond to the unique site of the 45S rDNA genes in this species revealed by FISH (Reck et al., 2011). Studies focused on rDNA localization have been used to propose a mode of chromosome evolution in South American species of Hypochaeris. As suggested by Ruas et al. (2005) and Weiss-Schneeweiss et al. $(2007,2008)$, structural rearrangements, including inversions and translocations, taking place in ancestral karyotypes bearing two or three $45 \mathrm{~S}$ rDNA loci have given rise to derived karyotypes with a unique $45 \mathrm{~S}$ rDNA locus. By interpreting the position of the rDNA in a phylogenetic context, Weiss-Schneeweiss et al. (2008) distinguished 7 chromosome groups among the South American Hypochaeris. The position of the 45S rDNA in H. catharinensis placed this species in the Patagonica group together with $H$. lutea and $H$. patagonica (Reck et al., 2011). Despite chromosome similarities, AFLP markers showed that $H$. lutea and $H$. patagonica do not belong to the same phylogenetic group (Tremetsberger et al., 2006; WeissSchneeweiss et al., 2008). Moreover, the recent AFLP study of Reck et al. (2011) revealed that $H$. catharinensis and $H$. lutea are closely related, supporting the relationship identified by the similar distribution of $45 \mathrm{~S}$ rDNA between these 2 species.
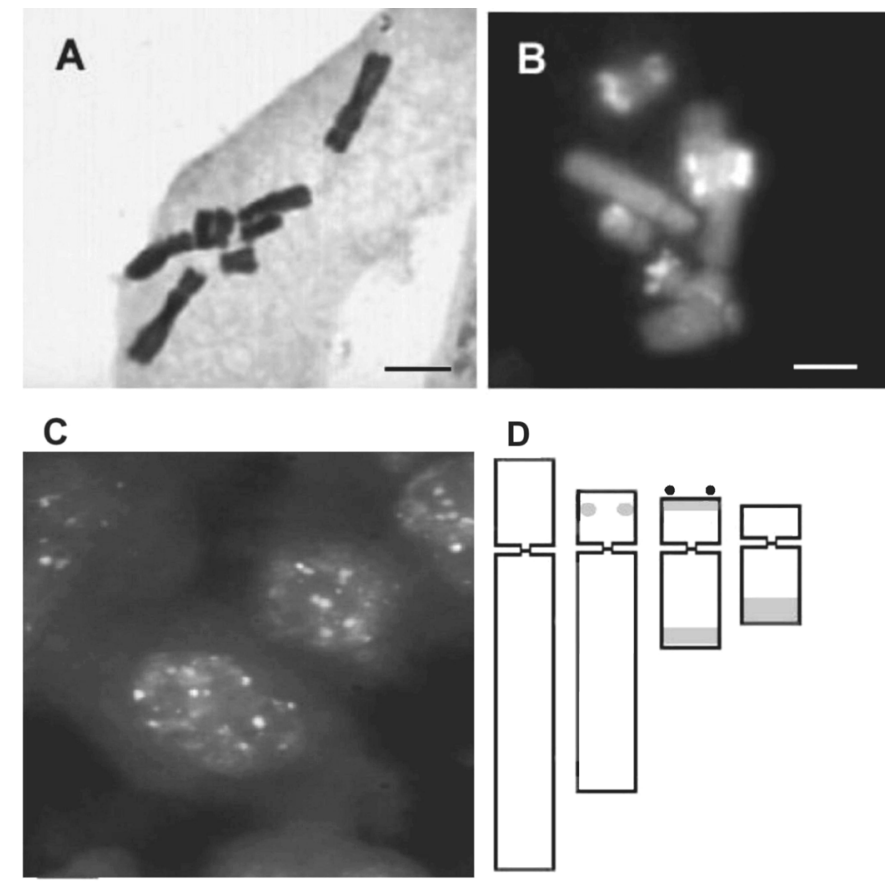

Figure 1. Chromosome features of Hypochaeris catharinensis. A. Conventional staining of mitotic metaphase (Pop. Cambará do Sul, RS, No. 28/06, FUEL-42237). B. Localization of chromomycin $\mathrm{A}_{3}\left(\mathrm{CMA}_{3}\right)$ banding. C. Interphase nuclei stained with $\mathrm{CMA}_{3}$. D. Ideogram illustrating the physical distribution of $\mathrm{CMA}_{3}$. Scale bar $=10 \mu \mathrm{m}$. 

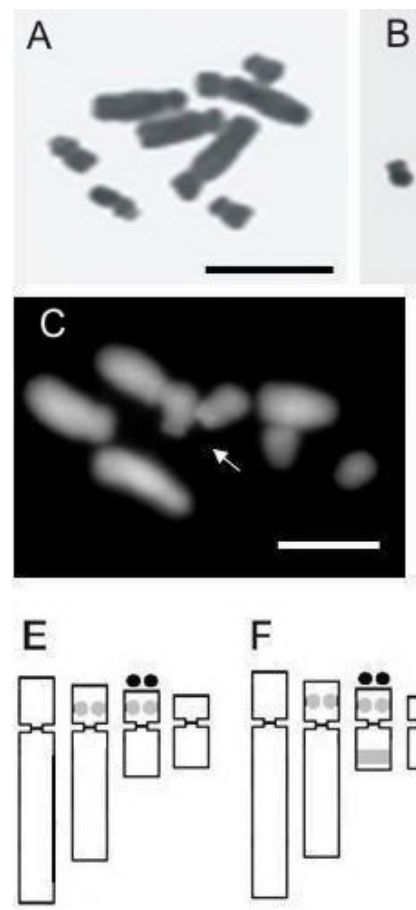

$\mathrm{F}$

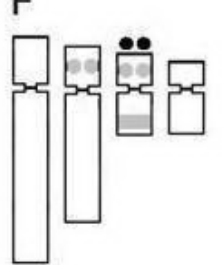

B
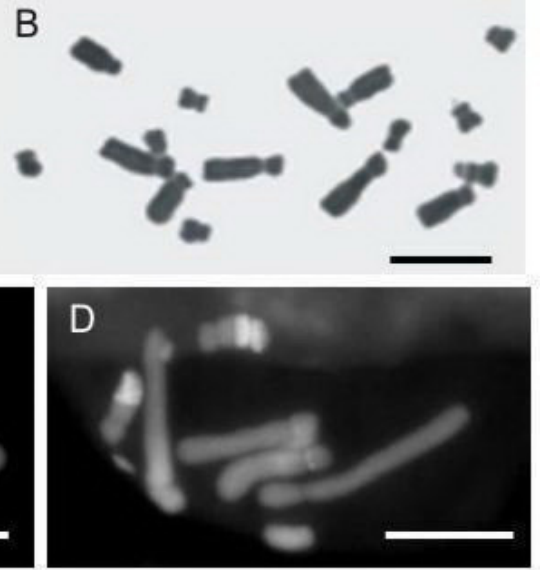

G

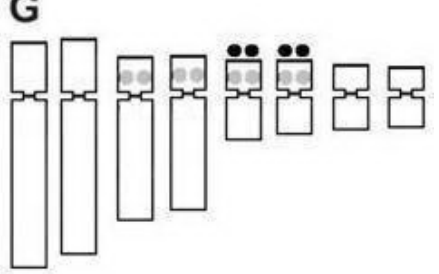

Figure 2. Chromosome features of Hypochaeris lutea. A. B. Mitotic metaphases of diploid (Pop. 17/06, Serra da Rocinha, RS) and polyploid cytotypes (Pop. 07/07, Serra do Rio do Rastro, Bom Jesus da Serra, SC). C. D. Mitotic metaphases showing the regular distribution of chromomycin $\mathrm{A}_{3}\left(\mathrm{CMA}_{3}\right)$ and the occurrence of unusual blocks of GC-rich heterochromatin on the large arms of chromosome pair 3 (Pop. 08/07, Highway between São Joaquim and Bom Jardim da Serra, SC). E. F. G. Ideograms illustrating the distribution of $\mathrm{CMA}_{3}$ in H. lutea. Scale bar $=10 \mu \mathrm{m}$.

The karyotypes of $H$. lutea for all 5 populations studied were similar, following the same pattern of the data previously published for this species (Ruas et al., 2005). A metaphase plate and ideograms representing the diploid populations of $H$. lutea are shown in Figure 2A, $\mathrm{E}$ and F, respectively. Small variation was observed in the position of the centromere of chromosome pair 3 that was identified as either metacentric ( $\mathrm{m}$-sat for 4 populations) or submetacentric (sm-sat, for population 08/07) with the following karyotype formulae: $2 n=8=2 \mathrm{~m}$ $+2 \mathrm{~m}$-sat $+4 \mathrm{st}$ and $2 n=8=2 \mathrm{~m}+2 \mathrm{sm}$-sat +4 st (Table 2). The population 07/07 (Bom Jesus da Serra, SC) of $H$. lutea was entirely polyploid with the karyotype formula of $2 n=16=4 \mathrm{~m}$ $+4 \mathrm{~m}$-sat +8 st chromosomes, revealing a novel cytotype for this species (Figure 2B and G). Satellites were identified on the short arms of all 4 copies of chromosome 3 in the tetraploid cytotype of $H$. lutea, highlighting the additive pattern of the 45S rDNA locus in this species. The additive distribution of 45S rDNA loci has been reported for other South American $H y$ pochaeris, for instance, the tetraploid cytotypes of $H$. taraxacoides (Weiss-Schneeweiss et al., 2008). In other polyploid cytotypes, such as $H$. incana, $45 \mathrm{~S}$ rDNA signals were seen on only 2 copies of the NOR chromosomes 2 and 3, whereas in $H$. caespitosa the 45S rDNA genes appeared as a single locus, whether the population was diploid or tetraploid (Weiss-Schneeweiss et al., 2008). Polyploidy is relatively frequent among the South American species of Hypocha- 
eris, occurring in almost $20 \%$ of the known species and thus suggesting that polyploidization is an active process in this group (Weiss-Schneeweiss et al., 2003, 2007, 2008). Whereas tetraploid individuals may coexist with diploids in the same population of some Hypochaeris species (Weiss-Schneeweiss et al., 2007), suggesting an autopolyploid origin, this was not the case with $H$. lutea, where all 37 individuals analyzed were polyploid. Whether or not this population is auto- or allopolyploid needs further investigation.

\section{Chromosome banding}

Fluorochrome banding with $\mathrm{CMA}_{3}$ was applied to chromosome preparations of 5 populations of $H$. catharinensis (Cambará do Sul, RS; Pico Montenegro, RS; Rancho Queimado, SC; Lages, SC; and São Joaquim, SC), revealing a novel pattern of GC-rich heterochromatin for Hypochaeris. Chromomycin staining identified strong positive signals distally located on the long arms of chromosomes 3 and 4 (Figure 1B and D). Strong CMA signals were also observed on the short arms of pair 3, adjacent to the 45S rDNA locus. Less intense signals were distinguished at the interstitial position, co-located to the $5 \mathrm{~S}$ rDNA locus (Reck et al., 2011) on the short arms of chromosome pair 2 (Figure 1B and D). These signals were confirmed as bright spots in the interphase nuclei of $H$. catharinensis (Figure 1C). Whereas the co-location of $\mathrm{CMA}_{3}$-positive bands with rDNA loci is common in Hypochaeris (Cerbah et al., 1998; Ruas et al., 2005) as well as in other plant groups (Galasso et al., 1995; Fukui and Nakayama, 1996; Vanzela et al., 2002), the unusual distribution of GC-rich heterochromatin identified in $H$. catharinensis differs from any pattern already described for other Hypochaeris species. Although we could not detect any AT-rich block in $H$. catharinensis, Reck et al. (2011) described a DAPI fluorescent signal located at the intersticial position on short arms of chromosome pair 4 of this species. Although of weak intensity, the presence of this DAPI-positive band in $H$. catharinensis has been the only report of ATrich heterochromatin in Hypochaeris. The amount and intensity of $\mathrm{CMA}_{3}$-positive signals and the presence of AT-rich band identified in the chromosomes of $H$. catharinensis (Reck et al., 2011) suggest the occurrence of dynamic processes of amplification and dispersion of heterochromatic segments in this species.

Fluorescent staining with $\mathrm{CMA}_{3}$ applied on metaphase chromosomes of all 5 populations of $H$. lutea revealed the same pattern already described for $H$. rozengurtii, a synonymy of H. lutea (Ruas et al., 2005). Chromomycin-positive signals of medium intensity were identified adjacent to the secondary constriction and satellites on the short arm of chromosome pair 3 , while additional signals of weak intensity were observed near the centromere on the short arms of chromosome pair 2 (Figure $2 \mathrm{C}$ and $\mathrm{G}$ ), collocated with the $5 \mathrm{~S}$ rDNA locus identified by Ruas et al. (2005). The population 08/07 (between São Joaquim and Bom Jardim da Serra, SC), revealed an unusual large block of GC-rich heterochromatin, located at the terminal position on long arms of chromosome pair 3 (Figure 2D and F), which was probably derived by events of amplification of heterochromatic segments in this population of $H$. lutea. DAPI bands were absent in the karyotypes of $H$. lutea.

The comparative karyotype analysis among populations of each $H$. catharinensis and $H$. lutea identified small variations in the size and morphology of the chromosomes of these species, and confirmed the constant pattern of the karyotypes of South American Hypochaeris. Nonetheless, the remarkable differences observed in the distribution of $\mathrm{CMA}_{3}$-positive bands 
in the karyotype of $H$. catharinensis contrasted with the relatively homogeneous pattern of the GC-rich blocks observed in other studies, especially in the South American species (Ruas et al., 2005). These results suggest that chromosome rearrangements associated with dispersion of heterochromatic segments are active processes acting on karyotype diversification of these species. In addition, the identification of a polyploid population in $H$. lutea confirms that polyploidization episodes are common among the South American Hypochaeris.

\section{ACKNOWLEDGMENTS}

Research supported by Conselho Nacional de Desenvolvimento Científico e Tecnológico (CNPq; \#201254/2003-4, \#201332/2003-5), Fundação de Amparo à Pesquisa do Estado do Paraná (Fundação Araucária; \#024/2007, Protocol \#9791), and Fundacion BBVA.

\section{REFERENCES}

Arano H and Saito H (1980). Cytological studies in family Umbelliferae, 5: Karyotypes of seven species in subtribe Seselinae. La Kromosomo 2: 471-480.

Azevêdo-Gonçalves CF and Matzenbacher NI (2007). O gênero Hypochaeris L. (Asteraceae) no Rio Grande do Sul, Brasil. Iheringia 62: 55-87.

Barghi N, Mugnier C and Siljak-Yakovlev S (1989). Karyological studies in some Hypochaeris species from Sicily. Plant Syst. Evol. 168: 49-57.

Bortiri E (1999). Flora fanerogamica Argentina. Asteraceae, Lactuceae: Hypochaeris. Conicet 63: 1-25.

Cerbah M, Coulaud J and Siljak-Yakovlev S (1998). rDNA organization and evolutionary relationships in the genus Hypochaeris (Asteraceae). J. Hered. 89: 312-318.

DeFilips RA (1976). Hypochoeris. In: Flora Europaea (Tutin TG, Heywood VH, Burges NA, Moore DM, et al., eds.). Vol. 4. Cambridge University Press, Cambridge, 308-310.

Fukui K and Nakayama S (1996). Chromosome Banding Methods. In: Plant Chromossomes: Laboratory Methods (Fukui K and Nakayama S, eds.). CRC Press, Boca Raton, 288.

Galasso I, Schmidt T, Pignone D and Heslop-Harrison JS (1995). The molecular cytogenetics of Vigna unguiculata (L.) Walp: The physical organization and characterization of 18S-5.8S-25S rRNA genes, 5S rRNA genes, telomere-like sequences, and a family of centromeric repetitive DNA sequences. Theor. Appl. Genet. 91: 928-935.

Hall KJ and Parker JS (1995). Stable chromosome fission associated with rDNA mobility. Chrom. Res. 3: 417-422.

Levan A, Fredga K and Sandberg AA (1964). Nomenclature for centromeric position on chromosome. Hereditas 52: 201-220.

Matzenbacher NI (1998). O Complexo "Senecionoide" (Asteraceae - Senecioneae) no Rio Grande do Sul, Brasil. Doctoral thesis, Universidade Federal do Rio Grande do Sul, Porto Alegre.

Mugnier C and Siljak-Yakovlev S (1988). Karyological study in some Yugoslavian populations of Hypochoeris (Compositae). Caryologia 40: 319-325.

Parker JS (1976). The B-chromosome system of Hypochaeris maculata. I. B-distribution, meiotic behavior and inheritance. Chromosoma 59: 167-177.

Reck M, Benício LM, Ruas EA, Rodrigues LA, et al. (2011). Karyotype and AFLP data reveal the phylogenetic position of the Brazilian endemic Hypochaeris catharinensis (Asteraceae). Plant Syst. Evol. 296: 231-243.

Ruas CF, Ruas PM, Matzenbacher NI, Ross G, et al. (1995). Cytogenetic studies of some Hypochaeris species (Compositae) from Brazil. Am. J. Bot. 82: 369-375.

Ruas CF, Vanzela ALL, Santos MO, Fregonezi JN, et al. (2005). Chromossomal organization and phylogenetic relationships in Hypochaeris species (Asteraceae) from Brazil. Genet. Mol. Biol. 28: 129-139.

Siljak-Yakovlev S, Bartoli A, Roitman G, Barghi N, et al. (1994). Etude caryologique de trois especes d'Hypochoeris originaires d'Argentine: H. chillensis, H. microcephala var. albiflora et H. megapotamica. Can. J. Bot. 72: 1496-1502. Stebbins GL (1971). Chromosomal Evolution in Higher Plants. Edward Arnold, London.

Tremetsberger K, Weiss-Schneeweiss H, Stuessy T, Samuel R, et al. (2005). Nuclear ribosomal DNA and karyotypes indicate a NW African origin of South American Hypochaeris (Asteraceae, Cichorieae). Mol. Phylogenet. Evol. 36: $102-116$. 
Tremetsberger K, Stuessy TF, Kadlec G, Urtubey E, et al. (2006). AFLP phylogeny of South American species of Hypochaeris (Asteraceae, Lactuceae). Syst. Bot. 31: 610-626.

Vanzela AL, Ruas CF, Oliveira MF and Ruas PM (2002). Characterization of diploid, tetraploid and hexaploid Helianthus species by chromosome banding and FISH with 45S rDNA probe. Genetica 114: 105-111.

Weiss-Schneeweiss H, Stuessy TF, Siljak-Yakovlev S, Baeza CM, et al. (2003). Karyotype evolution in South American species of Hypochaeris (Asteraceae, Lactuceae). Plant Syst. Evol. 241: 171-184.

Weiss-Schneeweiss H, Stuessy TF, Tremetsberger K, Urtubey E, et al. (2007). Chromosome numbers and karyotypes of South American species and populations of Hypochaeris (Asteraceae). Bot. J. Linn. Soc. 153: 49-60.

Weiss-Schneeweiss H, Tremetsberger K, Schneeweiss GM, Parker JS, et al. (2008). Karyotype diversification and evolution in diploid and polyploid South American Hypochaeris (Asteraceae) inferred from rDNA localization and genetic fingerprint data. Ann. Bot. 101: 909-918.

Weiss H, Stuessy TF, Grau J and Baeza CM (2003). Chromosome reports from South American Hypochaeris (Asteraceae). Ann. Mo. Bot. Gard. 90: 56-63. 